\title{
TEOLOGIA DA LIBERTAÇÃO: UM ACONTECIMENTO DISCURSIVO
}

\author{
JEANE HANAUER \\ (FACEMED-PR)
}

\begin{abstract}
RESUMEN Este texto examina, desde la perspectiva de la escuela francesa de Análisis del Discurso, el discurso de la Teología de la Liberación, cuyo principal representante es el padre Leonardo Boff. Analisando el conflicto entre este discurso y el de la Sagrada Congregación para la Doctrina de la Fe (ex Santo Oficio), presidida por el cardenal Ratzinger, pretendemos mostrar que la Teología de la Liberación constituye un acontecimiento discursivo, según la noción propuesta por Pêcheux (1997). La dimensión del acontecimiento se verifica, en este discurso, en la articulación que opera entre los preconstruidos del cristianismo y los preconstruidos del marxismo, intentando una alianza entre dos dominios de saber hasta entonces antagónicos.
\end{abstract}

Este texto é parte integrante de nossa dissertação (A Teologia da Libertação e o Conflito com o Vaticano - análise de uma formação discursiva em processo de reconfiguração, UFRGS, 2000), na qual examinamos o discurso da Teologia da Libertação, sob a perspectiva da escola francesa de Análise do Discurso (doravante $\mathrm{AD}$ ). Esta disciplina, por provocar uma ruptura no pensamento positivista da década de 60 , constitui a melhor fundamentação epistemológica e teórica para a investigação dos fenômenos discursivos, já que trata os aspectos sócio-ideológico-históricos como fundamentalmente constitutivos da linguagem.

Embora a Teologia da Libertação (TL, daqui em diante) apareça efetivamente na década de 60, a preparação do "terreno" para o seu surgimento começa bem antes disso, com sucessivos documentos da Igreja - sobretudo encíclicas papais - abordando, cada vez mais fortemente, questões sócio-político-econômicas vividas pelos cristãos. O representante mais conhecido desta teologia é o frei Leonardo Boff, quem o Vaticano, após sucessivas punições inquisitoriais, condenou ao "silêncio obsequioso".

$\mathrm{O}$ discurso da TL constitui, como veremos, uma ameaça à hegemonia discursiva da teologia tradicional. A TL representa, para a hierarquia católica, uma tentativa de desestabilização do seu discurso. Pretendemos mostrar, portanto, que a TL constitui um "acontecimento discursivo, ou seja, o ponto de encontro de uma atualidade e uma memória" (Pêcheux, 1997: 17). A TL encerra a dimensão da memória, que pode ser vista na repetição do já-dito desde a Rerum Novarum, e a dimensão do acontecimento, resultante da mobilização de dizeres até então interditados na formação discursiva (FD) católica: os dizeres provenientes da formação discursiva marxista. Dito de outra forma, a TL entrelaça fortemente estrutura e acontecimento.

Essa dimensão do acontecimento se verifica, na TL, na articulação que ela opera entre os preconstruídos do cristianismo e os preconstruídos do marxismo, numa tentativa 
HANAUER - Teologia da libertação: um acontecimento...

de aliança entre esses dois discursos. A TLé um discurso onde se verifica fortemente uma conjunção entre a memória e o novo, entre continuidade e reconfiguração. Ela instaura, na FD Católica, uma nova posição-sujeito, constituída na dispersão do discurso-outro, incorporado no discurso-UM, aproximando dois domínios de saber nunca antes aproximados: o marxismo e o cristianismo.

A dimensão da memória/continuidade está nesta ancoragem que a TL busca no discurso fundador (o de Cristo) e na retomada do já-dito, no exercício de repetição, de paráfrase de discursos fundantes na história da Igreja Católica. Charbonneau aponta isso num estudo comparativo sobre as encíclicas papais. Segundo ele,

Há pois, uma sequência muito significativa que se pode estabelecer em relação ao Magistério da Igreja: Rerum Novarum (15 de maio de 1891); Quadragesimo anno (15 de maio de 1931); Pacem in Terris (11 de abril de 1963); constituição Gaudium et Spes (Vaticano II); Populorum Progressio (26 de março de 1967); carta apostólica Octogesima adveniens (14 de maio de 1971); Instrução sobre a liberdade cristã e a libertação (22 de março de 1986). É a partir desse impressionante conjunto que a Teologia da Libertação pôde construir seu discurso que só é surpreendente para aqueles que tudo ignoram a respeito do Magistério da Igreja em matéria de doutrina social. (1986: 65- grifo nosso)

Acrescentaríamos a isso, falando em termos discursivos, que o discurso da TL é surpreendente também para aqueles que deliberadamente esquecem dessa doutrina social sempre-já-lá. É nesse sentido que o Vaticano, quando combate tão veementemente a TL, produz um silenciamento desse já-dito nos vários momentos fundantes da TL.

A dimensão do novo, do acontecimento, no discurso da TL, está na instauração de novos sentidos para a palavra divina, na ruptura com uma tradição de leitura, com a hermenêutica tradicional. O que acontece no discurso da TL, conforme Orlandi "é uma conversão da dêixis do discurso religioso" (1996: 111). Dessa forma, as várias leituras da Bíblia são atualizações diferentes de sua dêixis.

É exatamente nesse gesto de atualização que a TL se configura como uma leitura "não autorizada" da Bíblia, porque a intervenção do sujeito junto ao discurso do Sujeito (Cristo), operando uma desliteralização extrema, não permitida, é considerada, pelo Vaticano, uma transgressão.

A TL constitui um gesto de leitura da Bíblia que procura uma certa compatibilidade e não o conflito- com os princípios marxistas. Como mostra Orlandi, "a TL é um lugar de fala no qual o político resiste como tal" (1996:113), enquanto que "a função do discurso religioso em geral é o silenciamento do discurso político" (1987:19). O discurso da TL incorpora, no domínio do discurso teológico , o elemento político, instituindo a relação fé e política como necessária para que o texto bíblico seja pertinente, para que tenha algo a dizer nos dias atuais.

Para Guilhaumou e Maldidier, "o acontecimento discursivo não se confunde nem com a notícia, nem com o fato designado pelo poder, nem mesmo com o acontecimento construído pelo historiador. Ele é apreendido na consistência de enunciados que se entrecruzam em um momento dado." (1994: 166).

Nesse entrecruzamento que a TL realiza entre o discurso cristão e o discurso marxista, ela instaura uma nova ordem de sentidos em sua FD. É um discurso que desloca os limites 
Cadernos de Estudos Lingüísticos 48(2) - Jul./Dez. 2006

que separam a FD Católica do seu exterior. Ele toma enunciados da ordem do já-dito, sedimentados, que já foram mobilizados em inúmeras enunciações anteriores (as encíclicas papais, por ex.) e redireciona o seu sentido, inaugurando uma nova filiação de sentidos. Não é um discurso fundador, uma vez que retorna constantemente ao discurso de Cristo este sim, fundador - ao discurso da doutrina social da Igreja e aos dogmas do Catolicismo. Dentre esses dogmas, o de Maria é enfatizado constantemente no discurso da TL: " $A$ mariologia dogmática (Maria, Mãe de Deus, Virgem, Imaculada e Assunta) aqui é sempre mantida como o grande horizonte, no interior do qual, porém, se realça uma mariologia histórica, mais condizente com a realidade concreta da América Latina." (Boff, L. e Boff, C., 1985: 33, grifo nosso).

Essa reafirmação de dogmas como Maria e práticas como a veneração de santos, que separam a Igreja Católica das demais vertentes do Cristianismo (a Igreja Luterana, a Batista, as Testemunhas de Jeová, os Adventistas, etc ), comprovam a tese que estamos defendendo de que a TL não rompe com a FD Católica, e não representa, portanto, uma nova corrente do cristianismo (como ocorreu com Lutero e Calvino).

O já-dito da TL apóia-se também em São Francisco de Assis. O teólogo Leonardo Boff é frei franciscano e traz para o discurso da TL o conceito de pobre conforme a ótica deste santo. Segundo o próprio Boff: "eu penso e digo aquilo que Dom Helder repete muitas vezes: que São Francisco é o patrono da opção preferencial pelos pobres." ( Boff, L. e Boff, C.1985:33).

O discurso da TLé, pois, um discurso extremamente heterogêneo, cuja polifonia é camuflada por uma aparente unidade e univocidade. Dentre as várias posições-sujeito com as quais o sujeito da TL debate, uma é a da Sagrada Congregação para a Doutrina da Fé (SCDF, daqui em diante) que ocupa, na FD Católica, um 'lugar' enunciativo que não pretende ceder ou intercambiar com a TL. A SCDF dirige-se à TL sempre num tom de censura, porque ela toca em questões sensíveis que, segundo a hierarquia católica, não são da ordem do teológico. A TL, portanto, deve ser silenciada.

As críticas da SCDF são incorporadas pela TL sob uma operação de negação, resultando disso um discurso tenso, polêmico. Diante das acusações que lhe são imputadas, a TL se configura como um discurso de defesa, que pretende garantir seu lugar enunciativo, numa disputa de espaço com o discurso da SCDF. Verificamos assim uma sucessão de réplicas entre ambos. Em sua argumentação, buscando legitimar-se, ambos os discursos sustentam-se na palavra divina - o discurso fundador (Orlandi, 1993)- cada um, no entanto, com sua leitura própria.

Analisemos duas sequências do discurso da TL, onde se verifica essa operação de negação do discurso-outro:

a) "Porque um só é o vosso guia, o Cristo" (MT, 23,10).Se assim é, para um teólogo da libertação o materialismo e ateísmo marxistas não chegam a ser sequer uma tentação. (Boff, L. e Boff, C. 1986: 46)

b) No que tange à implosão do socialismo, afirmam os teólogos da libertação que o marxismo não foi jamais o centro de sua teologia. (Regidor, 1996:24) 
HANAUER - Teologia da libertação: um acontecimento...

Nestas sequências, o sujeito da TL interioriza as acusações da SCDF acerca do diálogo da TL com o marxismo, para melhor negá-las. Os enunciados formulados pelo sujeito da SCDF constituem o que não pode circular no interior da TL. Por essa razão, eles devem ser desqualificados, pelo viés da negação, para serem refutados.

A negação é a marca mais freqüente no discurso da TL. Diríamos até que estamos analisando um discurso que, em seu processo de interlocução, mais nega do que afirma, em função das freqüentes críticas que lhe são dirigidas. A negação é um dos mecanismos que sinalizam a presença de enunciados provenientes de um outro discurso., ou seja, ela coloca os discursos em posição de delimitação recíproca (Maingueneau, 1989: 120). É uma operação que marca, neste caso, um limite entre o discurso da TL e o da SCDF, que, embora pertencentes ao mesmo domínio de saber, constituem posições-sujeito divergentes e introduzem fortemente a contradição no âmbito da FD Católica.

Entendemos que, no caso da TL, a negação assume um papel mais determinante no que tange ao esforço desse discurso para instaurar-se. Dizemos isso porque, embora todo discurso, ao negar o outro, esteja trabalhando para constituir-se, no caso da TL, esta tarefa se apresenta mais difícil, porque ela diverge de um discurso institucionalizado, com uma tradição de sentidos fortemente cristalizados. A TL está, portanto, na condição de alvo de um discurso que, de repente, tem sua hegemonia ameaçada e que, por sua vez, o toma como alvo da negação. A negação interna instaura, pois, a delimitação entre essas duas posições-sujeito inscritas na FD Católica, ao mostrar a não-coincidência entre seus saberes, revelando a diferença que reside em seu interior.

Por isso, o trabalho da TL, no sentido de dizer o que tem a dizer, não é tão árduo quanto o seu trabalho de defender-se do discurso adversário, tendo que refutá-lo para se instaurar.

Na verdade, o que a TL diz defender é um resgate do cristianismo original. O projeto de Deus, anunciado pelos profetas e pelo próprio Jesus Cristo, tem uma dimensão política, o que se percebe em várias passagens bíblicas, como na que segue: "Ninguém construirá para outro morar, ninguém plantará para outro comer, porque a vida do meu povo será longa como das árvores, meus escolhidos poderão gastar o que suas mãos fabricarem. Ninguém trabalhará inutilmente, ninguém gerará filhos para morrerem antes do tempo..." (Isaías, 65,22 ))

Como evidencia este texto, essa preocupação com a condição social do povo é antiga, remontando mesmo a Isaías - portanto, ao Antigo Testamento. O que verificamos, portanto, é que há um esquecimento, por parte da teologia tradicional, do projeto original de uma nova sociedade, proposto por Cristo:"o Espírito do Senhor está sobre mim, porque ele me consagrou com a unção, para anunciar a Boa Notícia aos pobres; enviou-me para proclamar a libertação aos presos e aos cegos a recuperação da vista; para libertar os oprimidos, e para proclamar um ano de graça do Senhor." (Lucas, 4,18 - grifo nosso)

Constatamos, portanto, que a opção preferencial pelos pobres, posta em prática pela TL, tem sua origem não em Medellín (na $2^{\mathrm{a}}$ Conferência Geral do Episcopado LatinoAmericano) mas no discurso fundador de Cristo. A TL mobiliza, pois, esse discurso fundador e o atualiza para os dias atuais.

Isto nos faz constatar que a TL constrói seu discurso sobre uma ampla dispersão de discursos: o que ela propõe retoma o que encontra-se já-lá no Antigo Testamento, retoma 
o discurso fundador de Cristo, os pronunciamentos dos papas nas encíclicas e as conferências episcopais. Em outras palavras, funda-se sobre o já-dito, a estrutura.

Para explicar melhor este já-dito, faz-se necessário aqui mobilizar o conceito de memória discursiva, fundamental para os propósitos deste trabalho. Esta noção é introduzida na $\mathrm{AD}$ por Courtine. $\mathrm{O}$ autor esclarece, previamente, que não se trata da memória psicológica, individual, mas de uma memória social, histórica. Subjacente à formulação da noção de memória discursiva, está a preocupação do autor com a necessidade de articular a AD com a história. Para isso, ele se sustenta nos trabalhos de Foucault e Pêcheux. Courtine retoma a afirmação de Foucault, de que

pode-se supor que há, muito regularmente nas sociedades, uma espécie de desnivelamento entre os discursos: os discursos que "se dizem" no correr dos dias e das trocas, e que passam com o ato mesmo que os pronunciou; e os discursos que estão na origem de certos atos novos de fala que os retomam, os transformam ou falam deles, ou seja, os discursos que, indefinidamente, para além de sua formulação, são ditos, permanecem ditos e estão ainda por dizer. (Foucault,1996: 22)

Com base nisso, Courtine afirma que a noção de memória discursiva concerne à 'existência histórica do enunciado' no seio das práticas discursivas reguladas pelos aparelhos ideológicos. (1981: 53). Para o autor, a memória discursiva deve ser pensada a partir da articulação entre o interdiscurso e o intradiscurso, ou seja, entre o nível de formação dos elementos de saber e o nível de seqüencialização desses elementos (o 'fio' discursivo). Esta articulação possibilita recuperar, na análise de uma seqüência discursiva, toda a rede de formulações em que esta seqüência esteve inscrita, associando-a a um domínio de memória. Conforme Courtine,

é a partir do domínio de memória que será caracterizada a formação dos enunciados e que serão analisados os efeitos que produzem ao seio de um processo discursivo a enunciação de uma seqüência discursiva determinada (efeitos de retomada, de redefinição, de transformação; mas também efeitos de esquecimento, de ruptura, de denegação do já-dito). Acrescentamos que o domínio de memória consiste em uma "pluralidade contraditória" de seqüências discursivas... (1982:2534)

Mariani (1996) trabalha com o conceito de memória discursiva vinculado à noção de esquecimento. Ela define a memória como um processo histórico resultante de uma disputa de interpretações para os acontecimentos presentes ou já ocorridos. Sendo assim, a hegemonia de uma interpretação implica no esquecimento de outras. Ou seja, para que determinados sentidos sejam dominantes, outros sentidos possíveis são esquecidos.

Portanto, o que a TL diz, na verdade, são coisas que já foram ditas no discurso fundador, mas também já foram esquecidas. Ela apenas mobiliza sentidos que ficaram interditados, em nome de outros sentidos que adquiriram hegemonia no discurso da teologia tradicional. Ou seja, o discurso fundador do cristianismo - a libertação dos oprimidos foi esquecido para fortalecer e priorizar a espiritualidade, os dogmas, etc.

A essa estrutura, a TL articula o novo, o acontecimento, atualizando o sempre-já-lá desses discursos aos quais ela retorna. Essa atualização reside no fato de que a TL, incorpora, à FD Católica, saberes oriundos da FD Marxista. Nesta incorporação reside, pois, o 
HANAUER - Teologia da libertação: um acontecimento...

acontecimento: para levar a cabo a opção pelos pobres, sempre-já-lá, a TL recorre à análise marxista, que, até então, era o que não podia ser dito na FD Católica.

Conforme Pêcheux (1997), o discurso é estrutura e acontecimento. Estas duas dimensões apresentam-se fortemente articuladas na TL e daí deriva seu caráter de acontecimento discursivo. O que confere à TL o estatuto de acontecimento discursivo é também o fato de que a sua repercussão faz o Vaticano trazer de volta à cena religiosa uma prática aparentemente esquecida e desaparecida, verificada na Igreja Católica já em 1232 e oficialmente instituída em 1542: a Santa Inquisição.

Criada pelo papa Paulo III, a então Sagrada Congregação da Inquisição Romana e Universal (ou Santo Ofício), corte suprema de resolução das questões ligadas à fé e à moral, existe ainda, presidida pelo cardeal Joseph Ratzinger, só que sob uma nova designação: Sagrada Congregação para a Doutrina da Fé. (cf. por ex., Messori, 1994:9)

Entendemos o processo de designação conforme proposto por Guimarães: " a relação de designação é uma relação instável entre a linguagem e o objeto, pois o cruzamento de discursos não é estável, é ao contrário, exposto à diferença." (1995:74). Filiada também a esta perspectiva, Grigoletto acrescenta que "o objeto não estabelece pura e simplesmente, através da referência, uma relação direta com o mundo, mas é constituído por uma relação de discursos em confronto. E, nesse sentido, interessa ao analista do discurso o que o cruzamento desses discursos não deixa designar, silenciando sentidos não desejáveis para determinado momento da enunciação." (2000: 112-13- grifo nosso)

Sendo assim, o processo de designação que substitui o nome Sagrada Congregação da Inquisição Romana e Universal por Sagrada Congregação para a Doutrina da Fé produz um silenciamento de sentidos. Silencia-se, através dessa renomeação, que a Igreja Católica, no âmbito da Inquisição, já praticou muitos outros atos que resultaram no silenciamento, na abjuração da fé, na abjuração de pontos de vista e na abjuração de conhecimentos, na tortura e condenação à morte.

Silencia-se, por conseguinte, que a SCDF continua praticando a Inquisição e que Boff foi submetido a um processo nos moldes do Santo Ofício. Esse silenciamento de sentidos indesejáveis possibilita à SCDF que a sua posição-sujeito seja reconhecida como hegemônica na FD Católica e que seja preservado o direito de censurar o que pode ser dito nessa FD. A ponto de, em 1985, 443 anos após sua instituição, o ex-Santo Ofício acusar, julgar e punir o frei Leonardo Boff, condenando-o ao "silêncio obsequioso", em função do livro "Igreja, Carisma e Poder". Assim procedendo, o discurso da SCDF mostra-se fortemente autoritário, não reversível, sendo essa posição-sujeito o censor que controla $o$ que pode e deve ser dito na FD Católica, na tentativa de impedir a transformação desse dizer.

Importante assinalar, porém, que a SCDF não acusa o mencionado livro de conter heresias. Essa designação também é submetida à política do silêncio, pela qual "se apagam os sentidos que se quer evitar ". (Orlandi, 1995: 76). Ao invés de tachar, portanto, as afirmações de Boff como hereges, a censura é feita pelo cardeal Ratzinger nesses termos: "Falta às vezes a devida moderação, fruto da caridade, da justiça e do respeito pelas pessoas e instituições da Igreja. O tom usado é, pelo contrário, polêmico, difamatório, até mesmo panfletário, absolutamente impróprio para um teólogo." (Ratzinger, in: Boff, 
Cadernos de Estudos Lingüísticos 48(2) - Jul./Dez. 2006

1994:270). Ainda: “a Congregação sente-se na obrigação de declarar que as opções analisadas de Frei Leonardo Boff são de tal natureza que põem em perigo a sã doutrina da fé, que esta mesma Congregação tem o dever de promover e tutelar.” (idem, 341- grifo nosso) .

Como se percebe, é a mesma acusação que retorna, o já-dito sendo retomado, embora submetido a uma operação de silenciamento que atualiza o dizer, "varrendo para debaixo do tapete" o que não deve mais ser dito. Interessa ao analista do discurso, vale lembrar, justamente "o que está debaixo do tapete". Nesse sentido, como parte da memória discursiva em torno da Santa Inquisição ressoa também o fato de que, não casualmente, os hereges famosos condenados pelo Santo Ofício eram, como Leonardo Boff, franciscanos, em sua maioria, segundo o que descreve o próprio Manual dos Inquisidores:

Durante o pontificado de Urbano, em Viterbo, que sediava então a Cúria Romana, foram condenados,
entregues ao braço secular e queimados nove outros frades da ordem de São Francisco. (...) O
bispo e o inquisidor de Marselha condenaram e mandaram queimar como hereges contumazes
quatro frades franciscanos, cujos nomes, que não consegui registrar, figuram nos autos do processo.
(Eymerich, 1993:45)

Episódio semelhante à perseguição de Boff se deu por ocasião da Reforma Protestante (1517). A Reforma e a TL constituem dois momentos de crise interna da Igreja Católica bastante semelhantes. Lutero, cujas críticas, inclusive, eram de ordem semelhante às da TL, denunciava, entre outras coisas, a venda de indulgências e defendia a livre interpretação da Bíblia. É excomungado pelo Papa Leão X e cria uma nova religião, o Protestantismo. Em termos discursivos, surge uma outra região no complexo da FD Religiosa.

Cattelan, analisando a TL sob a perspectiva de Bakhtin, afirma que

a TL representa para a Igreja Católica a possibilidade de desestabilização de uma estrutura hierárquica de poder que não quer ser desfeita. Do ponto de vista discursivo (e este perigo é maior, por envolver a palavra - nada pior do que uma instância ser entendida como portadora de um discurso vazio), a TL representa a ruptura e a destruição de uma hegemonia discursiva que, em sendo superada, tem, por decorrência, desmantelada toda a organização que o discurso permitiu construir. (1996:148)

Concordamos com o autor, ressalvando, no entanto, que a TL não chega a provocar essa ruptura. Em que pesem as críticas e as diferenças, o discurso da TL continua inscrito na FD Católica. Diferentemente da Reforma de Lutero, a TL realiza, no interior da FD Católica, o entrecruzamento de enunciados desta FD com enunciados da FD Marxista, produzindo o deslocamento das fronteiras da FD Católica. No entanto, esse deslocamento não produz ruptura neste domínio de saber, ou seja, não ocorre o surgimento de uma nova Igreja. Como mostra Dorneles, "nem todo o acontecimento discursivo produz rupturas na realidade simbólica capazes de desestruturá-la, afastá-la de cena, permitindo que uma nova face do real se mostre apreendida.” (199:160).

O que caracteriza a TL como um acontecimento discursivo é o fato dela funcionar como o lugar de atualização de dois domínios de memória antagônicos: o marxismo e o cristianismo. Vamos mobilizar, para efeitos de análise, duas formulações representativas desse antagonismo: 
HANAUER - Teologia da libertação: um acontecimento...

FD Católica: o comunismo é intrinsecamente perverso e não é possível admitir com ele colaborar em campo algum. (Papa Pio XI, Encíclica Divini Redemptoris , 19.03.1937, apud Charbonneau, 1986:47)

\title{
FD marxista: a religião é o ópio do povo.(Karl Marx, 1968)
}

Estas duas formulações enviam para saberes de FD antagônicas e a TL, ao entrelaçar as duas, precisa fazer com que certos saberes fiquem mais ou menos esquecidos, para que outros possam ser ditos: os da TL. Dá-se, nos termos de Indursky, a reorganização da memória discursiva. Para a autora,

\begin{abstract}
esses movimentos da memória permitem estabelecer uma ruptura com uma série de formulações e instaurar uma nova série de formulações. Ou seja, esse acontecimento discursivo está na origem de novos dizeres em torno desses dois enunciados inaugurais. Tais enunciados mantêm uma relação tensa tanto com a memória quanto com o discurso que se lhe opõe, estabelecendo novas relações com a estrutura. (no prelo)
\end{abstract}

A natureza deste acontecimento reside então justamente no entrelaçamento do que até então se repelia: o discurso cristão e o discurso marxista. Essa aproximação é proposta, por ex., por Gutiérrez:

\footnotetext{
Essa reflexão sobre o marxismo nos conduz a uma outra: há muito tempo, os cristãos têm temor de penetrar em análises que estão fora do seu mundo restrito. Se somente fôssemos considerar como coisas boas as coisas feitas pelos cristãos, não poderíamos nem acender a luz. A atitude de negar a análise marxista demonstra medo. E, cristãmente, o medo se opõe à fé. (...) A pergunta que devemos fazer não é se, como cristãos, devemos ou não aceitar a luta de classes. A questão é outra: como devemos agir, enquanto cristãos, para que a luta de classes termine? (apud Valverde, 1983: 75)
}

Concluímos, portanto, que as duas faces constitutivas do discurso - estrutura e acontecimento - apresentam-se fortemente articuladas no discurso da TL, que opera uma atualização do domínio discursivo católico. Esta atualização consiste, por um lado, num retorno ao discurso fundador de Cristo e, por outro, na apropriação de certas questões oriundas do discurso marxista.

Esta articulação entre dois discursos até então antagônicos provoca a instauração de uma nova posição-sujeito, responsável pela enunciação dos dizeres da TL e da produção de novos sentidos na FD Católica. Em última análise, esta posição-sujeito produz a reconfiguração deste domínio de saber.

\section{$\overline{\text { REFERÊNCIAS BIBLIOGRÁFICAS }}$}

BOFF, L. e BOFF, C. (1986). Como fazer Teologia da Libertação. Petrópolis: Vozes/IBASE.

BOFF, L.(1994). Igreja, Carisma e Poder. São Paulo: Ática.

BOFF, L.; BOFF, C. (1985). Teologia da Libertação no debate atual. Petrópolis: Vozes. 
CATTELAN, J. C. (1996). (1996). O Gênero discursivo religioso católico: uma materialização discursiva previsível. Dissertação de mestrado. Curitiba: Universidade Federal do Paraná.

CHARBONNEAU, P. (1986). Da Rerum Novarum à Teologia da Libertação. Rio de Janeiro: Loyola.

COURTINE, J. J. Analyse du discours politique. Langages (62): 9-127. Paris, Larousse, juin-1981. (1982). Definition d'orientations théoriques et construction de procédures en analyse du discours. Philosophiques, 9 (2): 239-64, oct.

DORNELES, E.F. (1999). O discurso do MST: um acontecimento na estrutura agrária brasileira. In: INDURSKY, F.; LEANDRO FERREIRA, M. C. Os Múltiplos Territórios da Análise do Discurso. Porto Alegre: Sagra-Luzzatto.

EYMERICH, F. N. (1993). Manual dos Inquisidores. (1376). Revisto e ampliado por Francisco de La Peña em 1578. Rio de Janeiro: Rosa dos Tempos; Brasília: Editora da Universidade de Brasília.

FOUCAULT, M. (1996). A Ordem do Discurso. São Paulo, SP: Edições Loyola.

GUILHAUMOU, J. ; MALDIDIER, D. (1994). Efeitos do arquivo. A AD no Lado da História. In: ORLANDI, E. P. (org.) Gestos de Leitura. Campinas: Editora da Unicamp.

GUIMARÃES, E. (1995). Os Limites do Sentido. Campinas: Pontes.

GRIGOLETTO, E. (2000). Sob o rótulo do novo, a presença do velho: análise do funcionamento das repetições e das relações divino/temporal no discurso da Renovação Carismática Católica. Dissertação de mestrado. UFRGS: PPG LETRAS.

INDURSKY, F. A análise do discurso e sua inserção no campo das ciências da linguagem. in: Discurso, Memória, Identidade. Porto Alegre: Sagra Luzzatto.(no prelo).

MAINGUENEAU, D. (1989). Novas Tendências em Análise do Discurso. Campinas: Pontes.

MARIANI, B. (1996). O Comunismo Imaginário; Práticas Discursivas da Imprensa Sobre o PCB (1922-1989). Tese de Doutorado. Campinas: Unicamp.

MARX, K. (1968). Introduction à la critique du droit de Hegel. in: MARX, K. \& ENGELS, F. Sur la religion. Paris: Éditions sociales.

MESSORI, V. (1994). Cruzando o Limiar da Esperança. São Paulo: Círculo do Livro.

ORLANDI, E. P. (1995). As Formas do Silêncio; no Movimento dos Sentidos. Campinas: editora da Unicamp. . (org.) (1993). Discurso fundador. Campinas: Pontes. (1996). Interpretação: autoria, leitura e efeitos do trabalho simbólico. Petrópolis: Vozes. (org.) (1987). Palavra, fé e poder. Campinas: Pontes.

PÊCHEUX, M. (1997). O Discurso: estrutura ou acontecimento. Campinas: Pontes.

REGIDOR, J. R. (1996). Vinte e cinco anos de Teologia da Libertação. in: BOFF, L. (org). A Teologia da Libertação, balanço e perspectivas. São Paulo, SP: Ática.

VALVERDE, A. J. (org.) (1983). Comunidade, Ecumenismo e Libertação. Coleção PUC-Estudos. São Paulo: Paulinas. 